\title{
Correction to: Estimating GFR prior to contrast medium examinations - what the radiologist needs to know!
}

\author{
Ulf Nyman ${ }^{1}$ • Jonas Björk ${ }^{2,3}$ • Sten-Erik Bäck ${ }^{4}$ - Gunnar Sterner ${ }^{5}$ • Anders Grubb ${ }^{4}$ \\ Published online: 16 March 2021 \\ (C) European Society of Radiology 2021
}

\section{Correction to: Eur Radiol (2016) 26:425-435 https://doi.org/10.1007/s00330-015-3842-9}

The original version of this article, published on 28 May 2015, unfortunately contained a mistake. The following correction has therefore been made in the original:

In table 4, the enzymatic value for Bilirubin ditaurate was incorrectly given as " -0.11 ". The correct value is " -11 ". The corrected table is given below.

The online version of the original article can be found at https://doi.org/ 10.1007/s00330-015-3842-9

Ulf Nyman

ulf.nyman@bredband.net

1 Department of Translational Medicine, Division of Medical Radiology, Skåne University Hospital, Malmö, Sweden

2 R\&D Centre Skåne, Skåne University Hospital, Lund, Sweden

3 Department of Occupational and Environmental Medicine, Lund University, Lund, Sweden

4 Department of Clinical Chemistry, Skåne University Hospital, Lund, Sweden

5 Department of Nephrology, Skåne University Hospital, Malmö, Sweden
Table 4 Major interferences with kinetic alkaline picrate (Jaffe) and enzymatic assays for creatinine determination. Adapted from reference [32]

\begin{tabular}{llll}
\hline Interferent & $\begin{array}{l}\text { Added } \\
\text { concentration }\end{array}$ & $\begin{array}{l}\text { Measured bias, } \mu \mathrm{mol} / \mathrm{L} \\
\text { (basal creatinine } 70 \\
\mu \mathrm{mol} / \mathrm{L} \text { ) }\end{array}$ \\
\cline { 2 - 4 } & & $\begin{array}{l}\text { Alkaline } \\
\text { picrate }\end{array}$ & Enzymatic \\
\hline Ascorbate & $10 \mathrm{mmol} / \mathrm{L}$ & +37 & -13 \\
Pyruvate & $2 \mathrm{mmol} / \mathrm{L}$ & +31 & No bias \\
Albumin & $40 \mathrm{~g} / \mathrm{L}$ & +21 & No bias \\
Glucose & $50 \mathrm{mmol} / \mathrm{L}$ & +19 & No bias \\
Creatine & $2 \mathrm{mmol} / \mathrm{L}$ & +16 & No bias \\
$\begin{array}{l}\text { Bilirubin ditaurate } \\
\text { Acetoacetate }\end{array}$ & $500 \mu \mathrm{mol} / \mathrm{L}$ & -18 & -11 \\
$\begin{array}{l}\text { Dopamine } \\
\text { Cephalosporins, } \\
\text { depending on } \\
\text { type }\end{array}$ & $1 \mathrm{mmol} / \mathrm{L}$ & No bias & No bias \\
\hline
\end{tabular}

Publisher's note Springer Nature remains neutral with regard to jurisdictional claims in published maps and institutional affiliations. 